\title{
Asphalt Concrete Mixtures: Requirements with regard to Life Cycle Assessment
}

\author{
Jan Mikolaj, Frantisek Schlosser, Lubos Remek, and Aurelia Chytcakova
}

University of Žilina, Univerzitna 8215/1, 01001 Žilina, Slovakia

Correspondence should be addressed to Lubos Remek; lubos.remek@fstav.uniza.sk

Received 23 April 2015; Accepted 14 June 2015

Academic Editor: Wenbin Yi

Copyright (C) 2015 Jan Mikolaj et al. This is an open access article distributed under the Creative Commons Attribution License, which permits unrestricted use, distribution, and reproduction in any medium, provided the original work is properly cited.

\begin{abstract}
Design of asphalt concrete, required properties of constituent materials and their mixing ratios, is of tremendous significance and should be implemented with consideration given to the whole life cycle of those materials and the final construction. Conformity with requirements for long term performance of embedded materials is the general objective of the Life Cycle Assessment (LCA). Therefore, within the assessment, material properties need to be evaluated with consideration given to the whole service life-from the point of embedding in the construction until their disposal or recycling. The evaluation focuses on verification of conformity with criteria set for these materials and should guarantee serviceability and performance during their whole service life. Recycling and reuse of asphalt concrete should be preferred over disposal of the material. This paper presents methodology for LCA of asphalt concrete. It was created to ensure not only applicability of the materials in the initial stage, at the point of their embedding, but their suitability in terms of normatively prescribed service performance of the final construction. Methods described and results are presented in a case study for asphalt mixture AC 11; I design.
\end{abstract}

\section{Introduction}

Design of the asphalt mixture in terms of material and mixture ratios must ensure that the criteria for withstanding all adverse conditions through the whole life cycle under real operating conditions are met. Building materials comprising the asphalt concrete layer have to ensure the carriage of freight transport, tangential strains from decelerations on intersections, high and low temperature conditions and UV radiation, and so forth. These adverse conditions are to be endured by embedded materials through the whole life cycle of approximately 20 years. The materials need to provide operational serviceability of the finished construction in this period. For materials to meet the criteria, a complex approach for testing needs to be adopted in order to verify material characteristics. This approach consists of a combination of experimental laboratory tests, which are derived from material application, and long term monitoring of selected road sections. Within the framework of experimental testing, ascertainment of deformational and fatigue properties of materials and their life expectancy is paramount. The long term monitoring supplements these laboratory tests.

\section{Deformation Properties}

For LCA of basic, normatively [1] prescribed parameters of asphalt mixtures, it is necessary to analyse deformational properties as well as the fatigue resistance and life expectancy derived from it. The parameters are defined in concordance with the stresses to which asphalt mixture material is subjected in real life service conditions.

Complex modulus $E^{*}[\mathrm{MPa}]$ is a characteristic which defines the deformational properties of asphalt mixtures and from which the stress levels of asphalt mixture material can be derived. Since the AC has viscoelastic material properties, their characteristics have to be derived from rheological parameters. Both viscous and elastic facets of material in relation to temperature may be ascertained as a complex modulus by testing at a two-point trapezoidal bending beam, the shape of which is shown in Figure 1 [2].

Frequency of stress induction, oscillation frequency, acting on samples is in the range of 6 to $25 \mathrm{~Hz}$, which matches real life loading conditions from vehicles acting on the asphalt concrete in the pavement surface. The test is performed at a temperature of $+15^{\circ} \mathrm{C}$ and an oscillation frequency of $10 \mathrm{~Hz}$. 


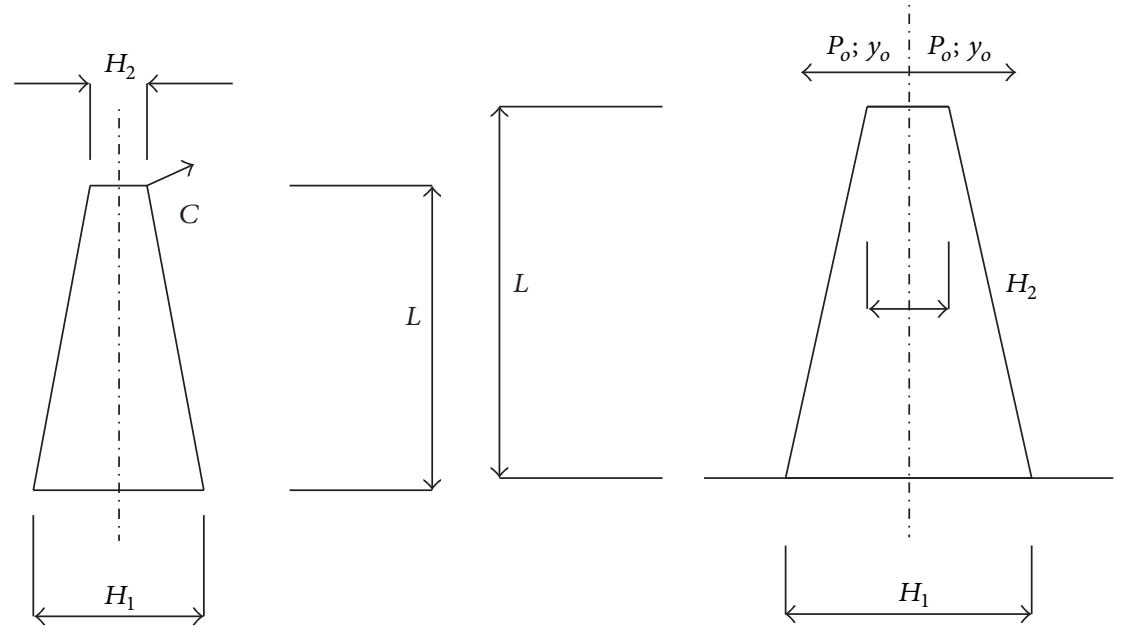

FIGURE 1: Shape of samples for complex modulus testing.

The deformational properties change in relation to the stress intensity, frequency, and temperature. Within the framework of research for this paper, asphalt mixture AC 11; I was tested for maximum levels of transport loading, for example, as a material intended for a wearing course layer. The testing was performed in compliance with the relevant standard [3]. The measured value of complex modulus was $E^{*} T=$ $15^{\circ} \mathrm{C} ; F=10 \mathrm{~Hz}=7576 \mathrm{MPa}$, measured at $15^{\circ} \mathrm{C}$ and $10 \mathrm{~Hz}$. The results are shown in Figure 2. The mixture consists of generic mineral aggregate and $5.5 \%$ of B50/70 binder. The continuance of changes in complex modulus is shown for each combination of frequency and temperature (for instance $27^{\circ} \mathrm{C}$ ). For a frequency of $1 \mathrm{~Hz}$ and differing temperature, the values of the complex modulus range from $1500 \mathrm{MPa}$ to $15000 \mathrm{MPa}$. The interval of temperatures considered ranged from $-10^{\circ} \mathrm{C}$ to $+27^{\circ} \mathrm{C}$. Based on measurements performed, we can assert that the change in temperature for different climate conditions (be it summer or winter) has significant impact on expected lifespan of asphalt bound materials.

The relationship can be also evaluated through the main curves. The advantage of main curves is that, after the introduction of the gas constant, complex modulus values for different temperatures and frequencies can be recalculated, and the relationship can be ascertained. Thus, the quality of asphalt concrete can be ascertained from relatively small number of tests. The method for main curve evaluation is shown in Figure 3.

\section{Fatigue: Service Life}

Fatigue is the rudimentary characteristic for ascertaining AC material service life. The fatigue parameters, which are specified by experimental measurements, are the premise for residual service life calculation. The input for this is the calculation of the stress levels, to which the material is subjected in the construction. The stress level is related to the strength of the material decreased by the fatigue characteristic. Strain calculation is based on a layered elastic half-space mathematical model [4], using the criterion of

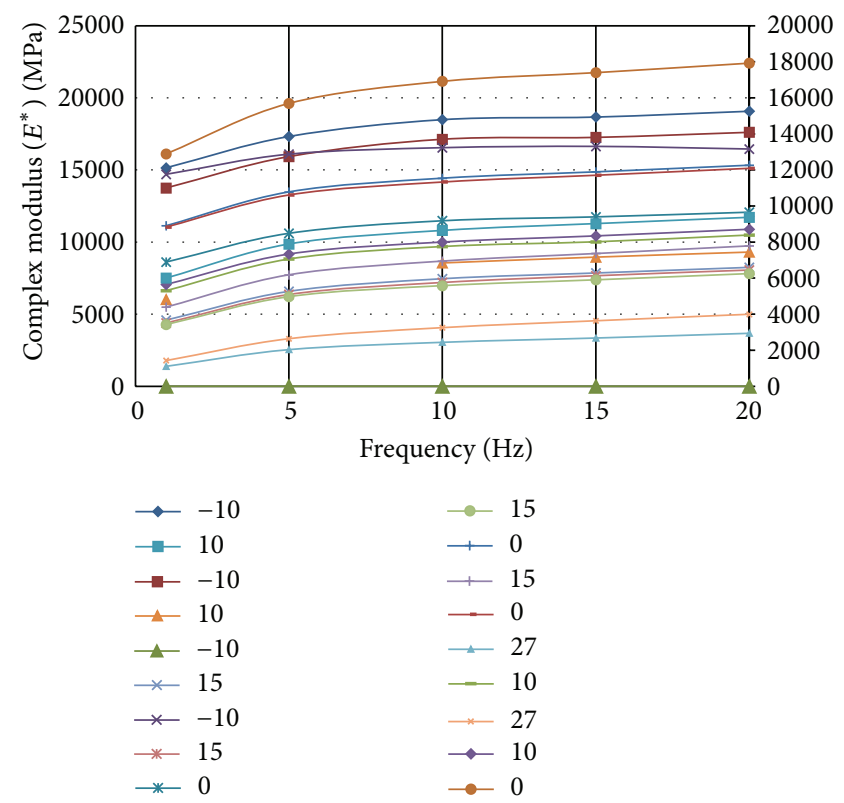

Figure 2: Relation of complex modulus $E^{*}$ to frequency and temperature.

crack initiation at the bottom edge of the asphalt bound layers.

The criterion of crack initiation at the bottom edge of the asphalt bound layers is considered satisfied, when (1) applies:

$$
\frac{\sigma_{r, i}}{S_{N} \times R_{i, i}} \leq 1,
$$

where $\sigma_{r, i}=$ radial stress on the bottom edge of the asphalt bound layer " $i$ " $[\mathrm{MPa}] ; R_{i}=$ maximum tensile stress produced at the point of failure after one load cycle of the pavement surface layer " $i$ " $[\mathrm{MPa}] ; S_{N}=$ fatigue characteristic for the asphalt pavement surface layer material. 


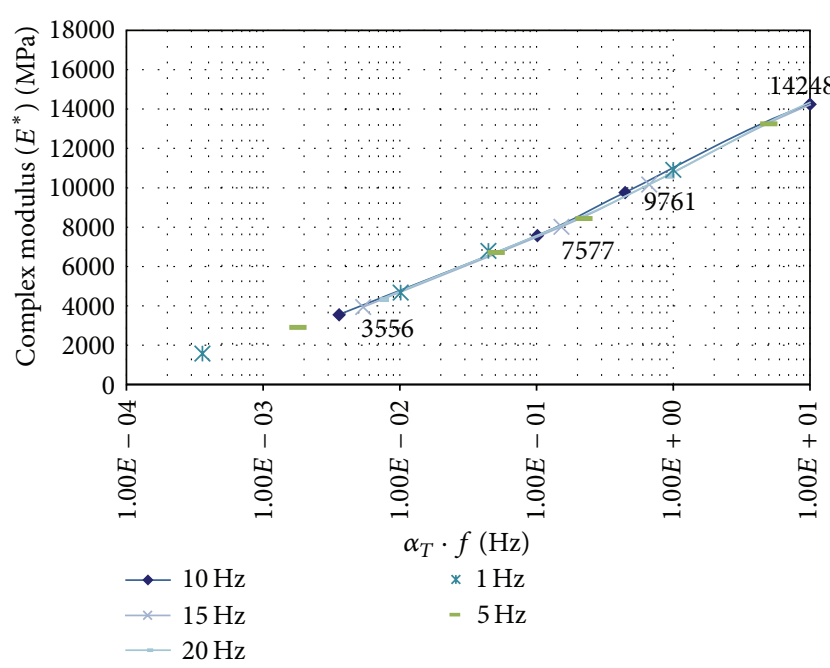

Figure 3: Main curves for AC 11; I.

The fatigue characteristic $S_{N}$ is dependent on the number of repetitions of standard axle load (SAL) and is derived from experimental measurements. It can be expressed as

$$
S_{N}=A-B \cdot \log N
$$

where $A, B$ = fatigue coefficients derived for a variety of asphalt bound materials and $N=$ number of repetitions of standard axles loads [SAL].

Consequently, after integrating (2) into (1), the service life of a layer can be calculated according to

$$
\log N_{i}=\frac{A \times R_{i}-\sigma_{r, i}}{B \times R_{i}}
$$

where $N_{i}=$ service life of layer " $i$ " in standard axle load [SAL]; $\sigma_{r, i}=$ calculated radial stress on the bottom edge of the pavement surface bounded layer " $i$ " [MPa]; $A, B=$ fatigue coefficients derived for a variety of asphalt or cement-bound materials.

Fatigue coefficients for AC I ascertained through experimental measurements should lie within these intervals $[2,5]$ :

$$
\text { Asphalt concrete I: } A=0.95-0.9, B=0.11-0.12 \text {. }
$$

3.1. Measurement of the Fatigue Characteristics. In accordance with the European standard [3], fatigue must be defined by means of linear regression represented by a logarithmic function. This function must be based on results, which represent the length of fatigue life $N_{i}$ for $\varepsilon_{i}$, chosen through the linear regression between the value of $\lg N_{i}$ and value of $\lg \varepsilon_{i}$ (fatigue resistance) according to

$$
\lg N_{i}=a+\left(\frac{1}{b}\right) \cdot \lg \varepsilon,
$$

where $N_{i}=$ conventional fatigue life of sample $i ; a=$ ordinate of the function; $1 / b=$ steepness of the function; $\lg \varepsilon=$ average value of $\lg \varepsilon_{i}$.
Service life can be calculated based on the same principle as in (1). The difference is that, instead of stress and strength assessment of the AC I material calculated in the layered elastic half space, proportional deformations on the bottom of the asphalt layers are used and the fatigue resistance is characterized by average elastic and permanent strain, derived by experimental measurements $[6,7]$.

Based on this procedure, it is imperative to ascertain the Wöhler curve by means of experimental tests, which will define loading cycles and strain expressed through parameter $\varepsilon_{6}$ and parameters $a, 1 / b$.

As research results for this paper, we present the relationship of the loading cycles and the amplitude of the asphalt concrete mixtures (AC) AC 11; I in Figure 4 and Table 1.

Fatigue value $\varepsilon_{6}$ is the relative deformation for 1 million loading cycles of test samples for one asphalt concrete mixture [8].

\section{Performance: Deterioration Rates}

Experimental fatigue measurements and related derived parameters form the basis for service life calculation. However, in real life application of AC mixtures, which form a pavement surface, other factors that cannot be simulated in those fatigue measurements impact the material. Therefore, other coefficients are included in the calculation to express fatigue reliability ratio in relation to real life AC mixture operation [6]. Second, a much more precise option is to perform measurements on real road sections on which service life is measured directly. In the research, the deformation progress of AC material was directly observed over a period of 10 years during which the material endured 7 million SAL loading cycles.

Since the fatigue characteristics are experimentally evaluated through deformational characteristics, elastic and plastic, the evaluation of service life in real operation was performed through longitudinal unevenness measurement, that is, through plastic deformation measurement.

The premise for these measurements was that pavement surface construction - foremost the subbase-does not influence the asphalt concrete in the surfacing. Therefore, besides longitudinal unevenness, bearing capacity of the construction also had to be ascertained to prove this assumption. Also, for creation of degradation models applicable to exactly defined conditions, traffic intensity and climatic conditions and air temperature and surface temperature would have to be regularly recorded in set intervals [9].

Longitudinal unevenness evaluation is done with the use of longitudinal unevenness progression models, that is, Pavement Performance Models [10-12]. These however express changes in the surfacing in relation to traffic loading. For our research objectives, it was necessary to record deformational changes of AC I material over a long term period by means of IRI, International Roughness Index. The measurements were performed by PROFILOGRAPH GE [13-15]. The results are expressed through IRI in $\mathrm{m} / \mathrm{km}$ according to

$$
\text { IRI }=\frac{1}{N-1} \cdot \sum_{i=2}^{N} T_{i},
$$


TABLE 1: Values of fatigue parameters for mix AC 11.

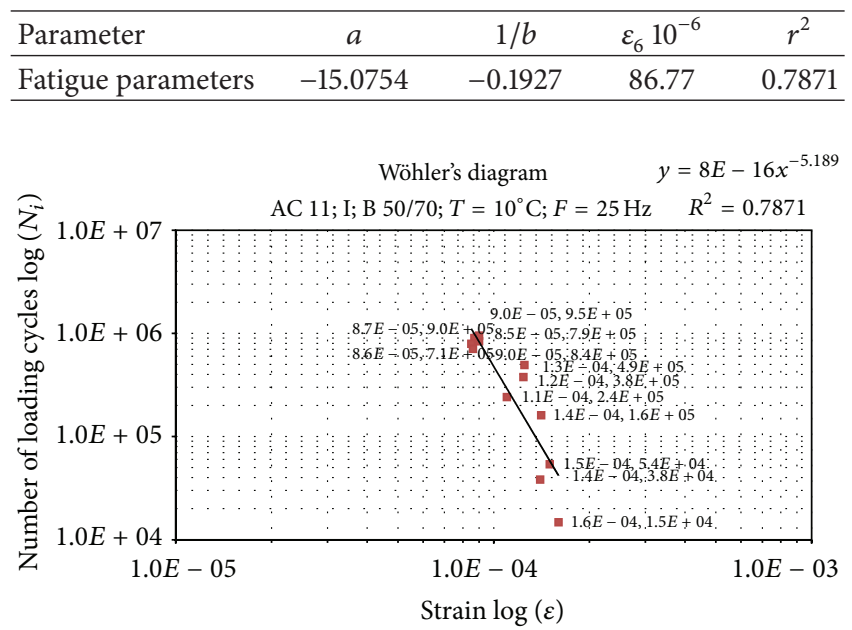

FIGURE 4: Wöhler's diagram for AC 11; I.

where $T_{i}=$ arithmetical average value of $T_{i}$ ordinates; $N=$ number of measurements.

Transverse unevenness is expressed through rut depth. Figure 5 illustrates surface characteristics.

The device measures unevenness by means of 16 railbound lasers at $20 \mathrm{~m}$ intervals. One of the measurements for a long term performance monitored (LTPPM) section is shown in Table 2.

Mathematical relationships between IRI SAL can be derived from IRI changes accrued by traffic loading recalculated to SAL. These were drawn for 1st class roads and motorways, both of which have AC 11; I surfacing, shown in Figures 6 and 7. The results shown represent a time span of 10 years. Three relationships were derived from measured values-linear, polynomial, and exponential. The polynomial function represents the measured values most accurately.

(i) Quadratic polynomial function for 1st class roads with AC 11; I surfacing:

$$
\begin{aligned}
y & =0,005 x^{2}-0,015 x+2,928 \\
R^{2} & =0,911 .
\end{aligned}
$$

(ii) Quadratic polynomial function for motorway with AC 11; I surfacing:

$$
\begin{aligned}
y & =0,006 x^{2}-0,059 x+2,012 \\
R^{2} & =0,924 .
\end{aligned}
$$

We can deduce from these charts that although the starting IRI values are different (1st class roads were constructed earlier), deformation accrued during the 10 years of the reference period and approximately 6 million loading cycles (SAL) is the same for both road sections-IRI rises to $1.5 \mathrm{~m} / \mathrm{km}$, which exactly fulfills the suppositions based on laboratory testing. Residual service life can be calculated

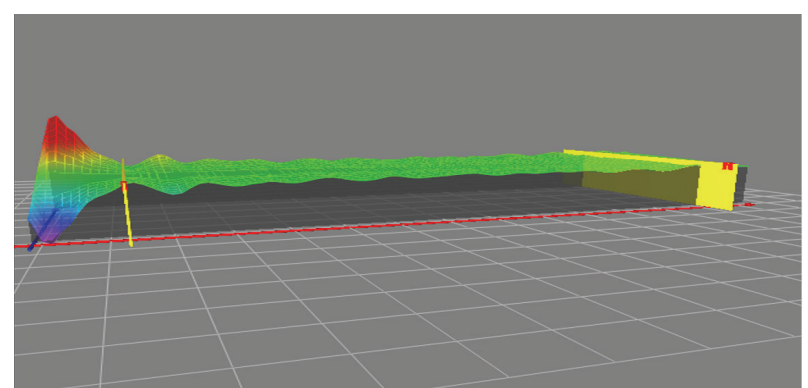

FIGURE 5: Surface characteristics-profilograph measurement.

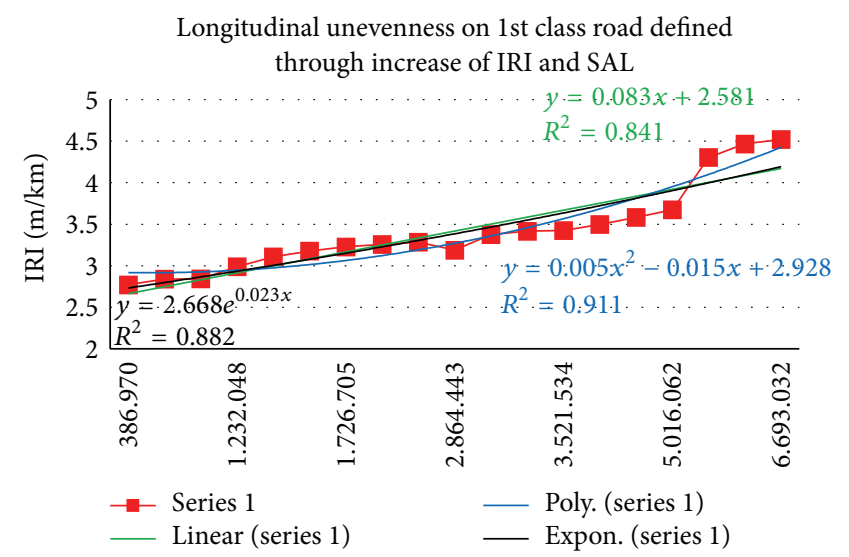

FIGURE 6: IRI deterioration for 1st class roads.

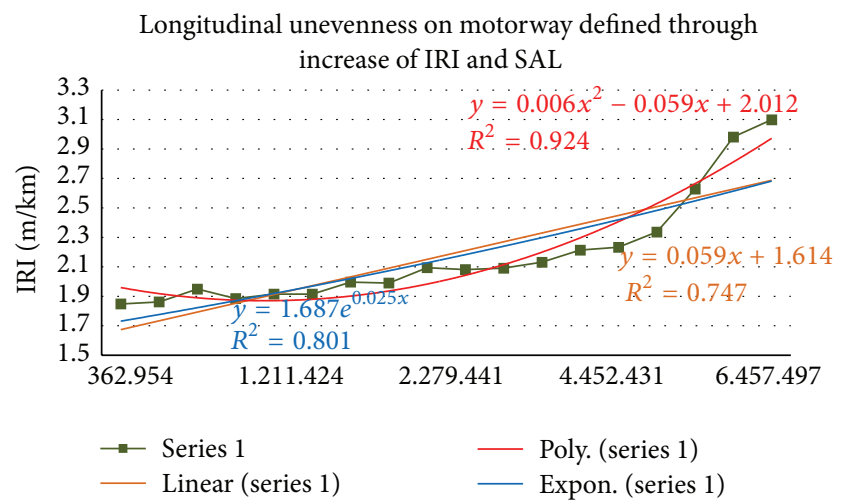

FIGURE 7: IRI deterioration for motorways.

from this degradation model. If we presume that the critical IRI value is $5 \mathrm{~m} / \mathrm{km}$, the AC 11; I material has a residual service life of 4 years. AC 11; I material embedded in the motorway however has a residual service life of almost 13 years. After this period, the AC 11; I material has to be disposed of or recycled. Another benefit of this analysis, in addition to asphalt concrete properties evaluation from the LCA viewpoint, is that the results are closely related to road user costs calculations and optimisation methods for maintenance, repair, and rehabilitation actions [16]. 


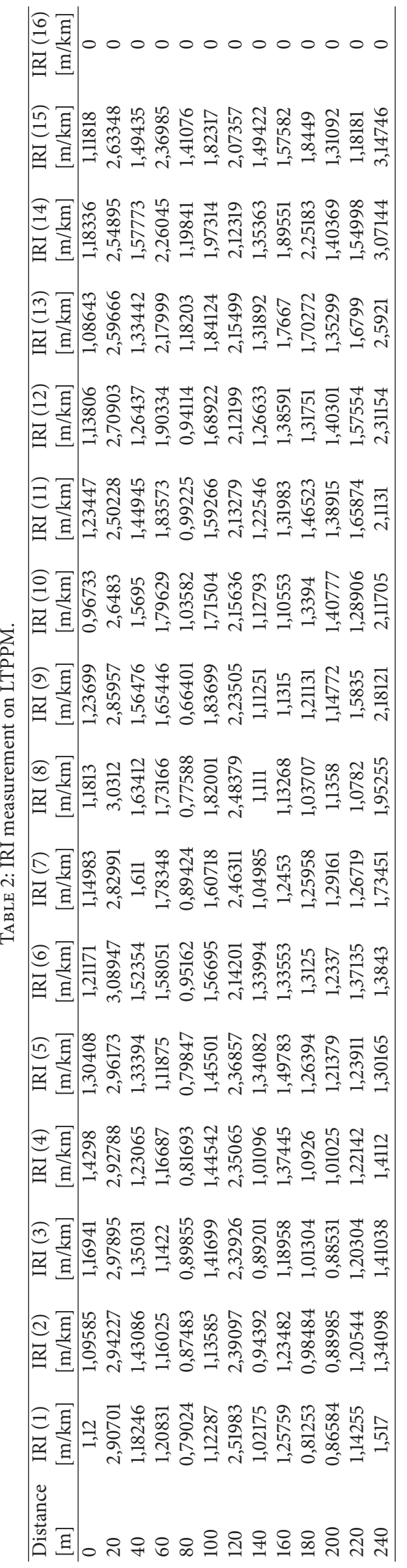




\section{Disposal and Recycling of Asphalt Concrete Materials}

Disposal of this material arises as an important question at the end of asphalt concrete service. A great advantage of asphalt concrete materials is that they can be recycled as part of new mixtures $[5,17]$. However, these newly recreated materials must conform to the same criteria as new ones. Therefore, recycled materials were subjected to all of the tests that new materials would be subjected to [15]. As a result of the research, we present a fatigue curve for asphalt concrete (Mix 1) AC 11 modified by PmB 70/100-83 (5.6\%), a fatigue curve for the same mix with the addition of recycled material (Mix 2), with 15\% recycled material and $4.9 \%$ bitumen and a fatigue curve for AC 11 with $40 \%$ recycled materials and $3.7 \%$ bitumen (Mix 3). The curves are presented in Figure 8 and Table 3.

Based on the results, it is possible to state that recycled materials conform to regulations [6] pertaining to their use. Construction using these materials can be reevaluated in the life cycle analysis using the same principles for maintenance, repair, and rehabilitation optimisation methods as layers made from new materials.

\section{Conclusion}

Material evaluation based on LCA is of tremendous importance since it is based only on ascertained characteristics of materials and can be applied in real life conditions.

In order to evaluate materials with regard to their life cycle, parameters must be firmly set to evaluate conformity of these materials. They must be evaluated for the design, for real life operation in the construction, and for their disposal or recycling.

Also for this reason, the evaluation methodology should include laboratory testing as well as in situ long term performance monitoring. Within the framework of the long term research, results from which are presented in this paper, material AC 11; I was evaluated for maximum levels of traffic loading. Changes of these characteristics were defined through fatigue testing of the material. Life expectancy of the material had to be calculated resulting from the traffic loading in order to define the fatigue parameters. Measurement results confirm that the AC 11; I material is able to bear the required amount of traffic loading.

Long term performance monitoring was performed to establish deterioration functions of surfacing made from AC 11; I material. The results of 10 years of long term performance monitoring confirm that deformation increase, measured in IRI for 600 thousand loading cycles (SAL) per annum, corresponds to 20 years of estimated service life demands. In addition, mathematical degradation models can be used for residual service life calculation of AC 11; I material. The importance of these calculations lies in the fact that they enable the calculation of the optimal year for repair and rehabilitation action.

The final stage of life cycle analysis is based on material disposal. AC materials share the benefit of being recyclablereusable in construction. The results of the measurement
TABLE 3: Ascertained fatigue parameters for mixtures with recycled material.

\begin{tabular}{lcccc}
\hline Parameter & $a$ & $1 / b$ & $\varepsilon_{6} 10^{-6}$ & $r^{2}$ \\
\hline Mix 1 & -22.3469 & -0.1310 & 193.10 & 0.7065 \\
Mix 2 & -41.3604 & -0.0817 & 135.77 & 0.5726 \\
Mix 3 & -89.2104 & -0.0397 & 166.38 & 0.8039 \\
\hline
\end{tabular}

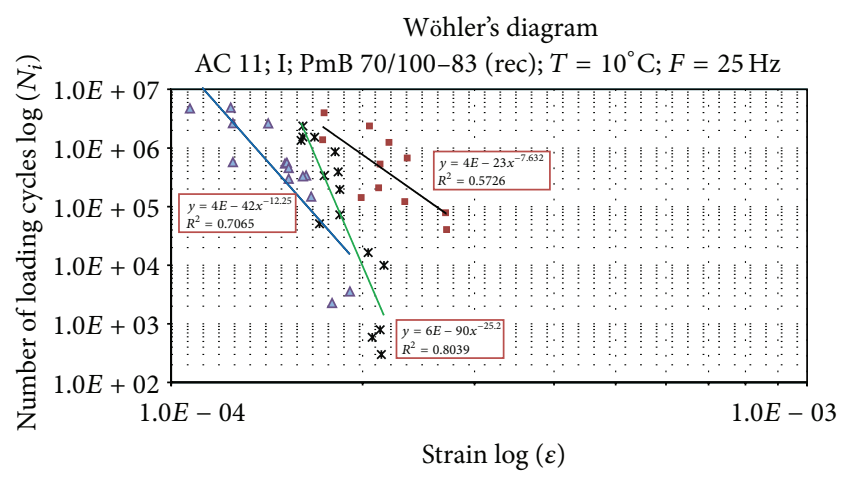

FIGURE 8: Fatigue curves for Mix 1-3.

show that if the right mix of recycled and new material is used, parameters comparable to new mixture are achievable. This has a direct impact on the economical aspect of AC construction design.

\section{Conflict of Interests}

The authors declare that there is no conflict of interests regarding the publication of this paper.

\section{Acknowledgments}

The research is supported by the European Regional Development Fund and the Slovak State Budget for the project "Research Centre of University of Žilina," ITMS 26220220183. Research activities in Slovakia are supported and project is cofounded from the resources of the EU.

\section{References}

[1] STN EN 13108-1 Asphalt Concrete, Bratislava, Slovakia, 2007.

[2] F. Schlosser, E. Šrámeková, and J. Šrámek, "Rheology, deformational properties and fatigue of the asphalt mixtures," Advanced Materials Research, vol. 875-877, pp. 578-583, 2014.

[3] European Nations, "Bituminous mixtures-test method for hot mix asphalt-part 24: resistant to fatigue," Tech. Rep. EN 1269724, European Nations, Brussels, Belgium, 2003.

[4] J. Čelko and J. Komačka, "Analysis of the pavement bearing capacity on the deflection bowl basis," in Proceedings of the 5th International conference on the Bearing Capacity of Roads and Airfields, vol. 1, pp. 609-617, Trondheim, Norway, 1998.

[5] F. Schlosser, J. Mikolaj, V. Zatkalikova, J. Sramek, D. Durekova, and L. Remek, "Deformation properties and fatigue of bituminous mixtures," Advances in Materials Science and Engineering, vol. 2013, Article ID 701764, 7 pages, 2013. 
[6] Ministry of Transportation of the Czech Republic, "Pavement design for roads," Technical Standard TP 170, Ministry of Transportation of the Czech Republic, Prague, Czech Republic, 2004.

[7] J. Žák, C. L. Monismith, and D. Jarušková, "Consideration of fatigue resistance tests variability in pavement design methodology," International Journal of Pavement Engineering, vol. 16, no. 1, pp. 91-96, 2014.

[8] European Committee for Standardization (CEN), EN 12697-26: Bituminous Mixtures-Test Method for Hot Mix Asphalt-Part 26: Complex Modulus, European Committee for Standardization (CEN), Brussels, Belgium, 2003.

[9] A. Chytčakova, Pavement performance models evaluation in relation with Pavement Management Systems [Dissertation thesis], University of Zilina, 2014.

[10] European Commission, COST 324-Long Term Performance of Road Pavements, Final Report of the Action, European Commission, Directorate General Transport, Luxembourg City, Luxembourg, 1997.

[11] H. P. Hong and S. S. Wang, "Stochastic modeling of pavement performance," The International Journal of Pavement Engineering, vol. 4, no. 4, pp. 235-243, 2003.

[12] PIARC, Highway Performance Monitoring Systems, Technical Committee 6 Road Management, 1997.

[13] Greenwood Engineering A/S, Users Guide to Profilograph for Windows. Version 1.22, Greenwood Engineering A/S, Brøndby, Denmark, 2007.

[14] J. Čelko, M. Decký, and M. Kováč, "An analysis of vehicle-road surface interaction for classification of IRI in frame of Slovak PMS," Maintenance and Reliability, vol. 1, no. 41, pp. 15-21, 2009.

[15] O. Kropáč and P. Múčka, "Deterioration model of longitudinal road unevenness based on its power spectral density indices," Road Materials and Pavement Design, vol. 9, no. 3, pp. 389-420, 2008.

[16] J. Mikolaj, F. Schlosser, and L'. Remek, "Life-cycle cost analysis in pavement management system," Communications, vol. 15, pp. 102-106, 2013.

[17] M. S. Pourtahmasb and M. R. Karim, "Performance evaluation of stone mastic asphalt and hot mix asphalt mixtures containing recycled concrete aggregate," Advances in Materials Science and Engineering, vol. 2014, Article ID 863148, 12 pages, 2014. 

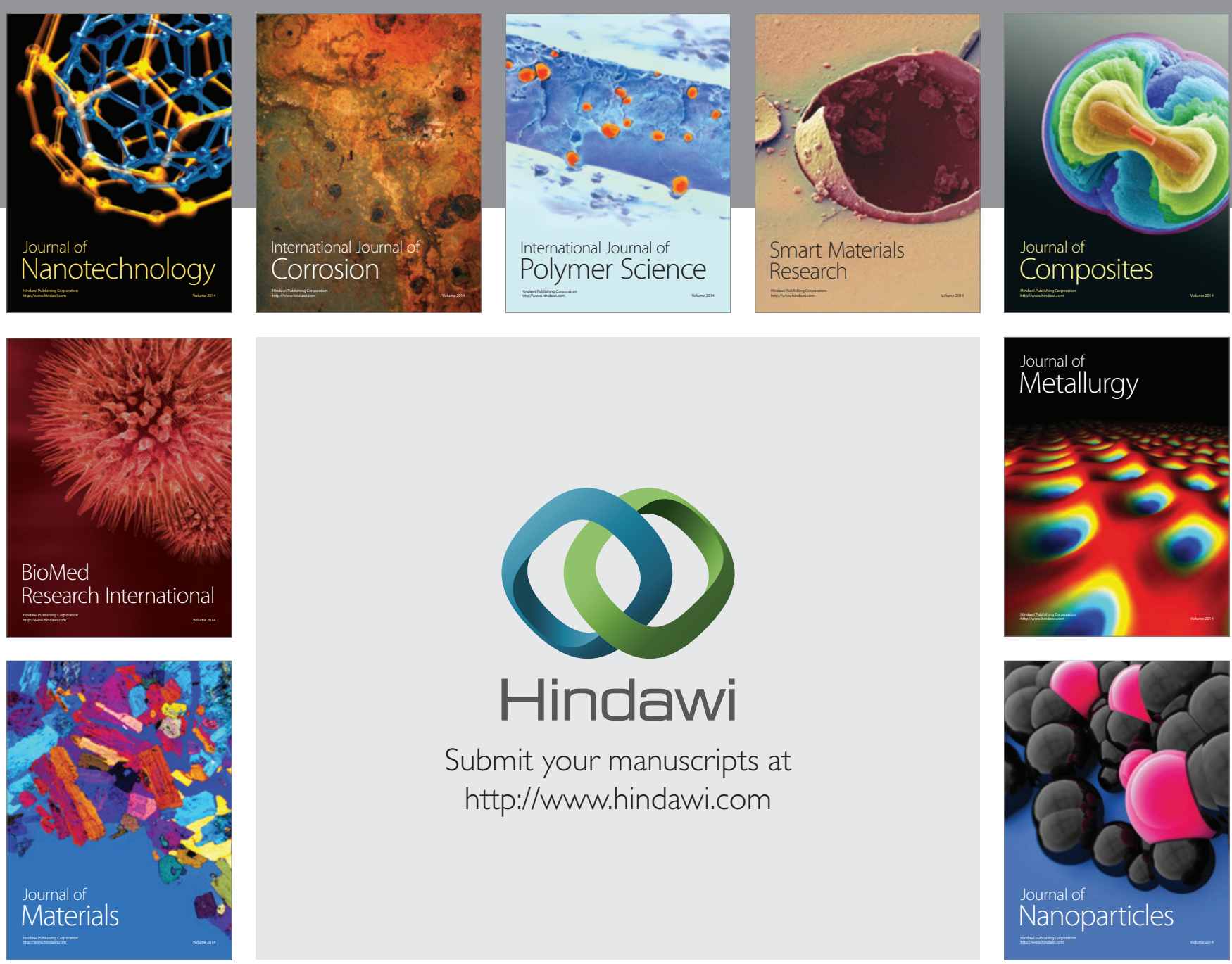

Submit your manuscripts at http://www.hindawi.com
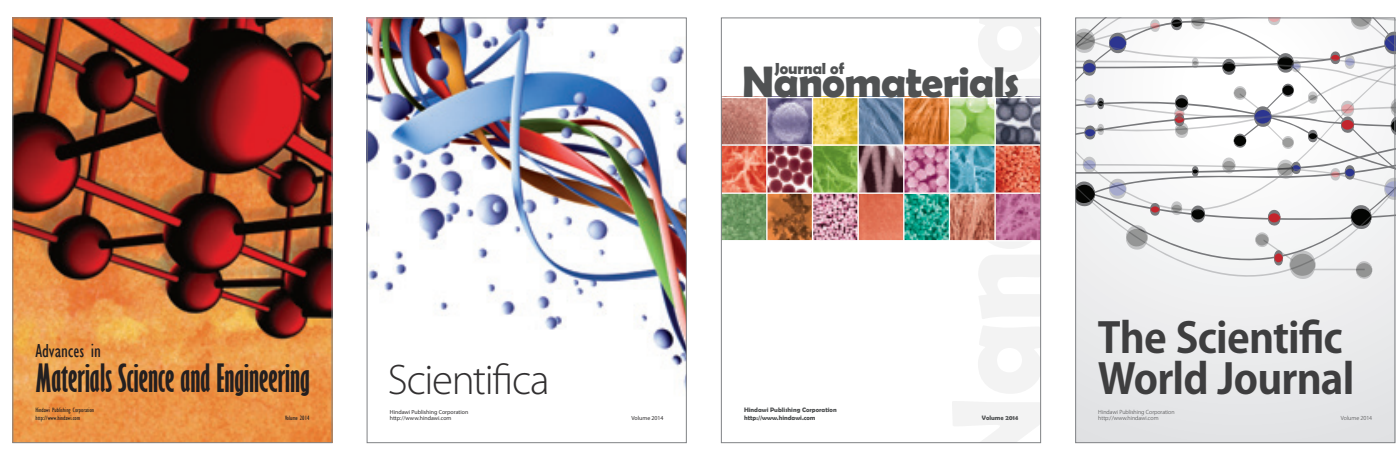

\section{The Scientific World Journal}
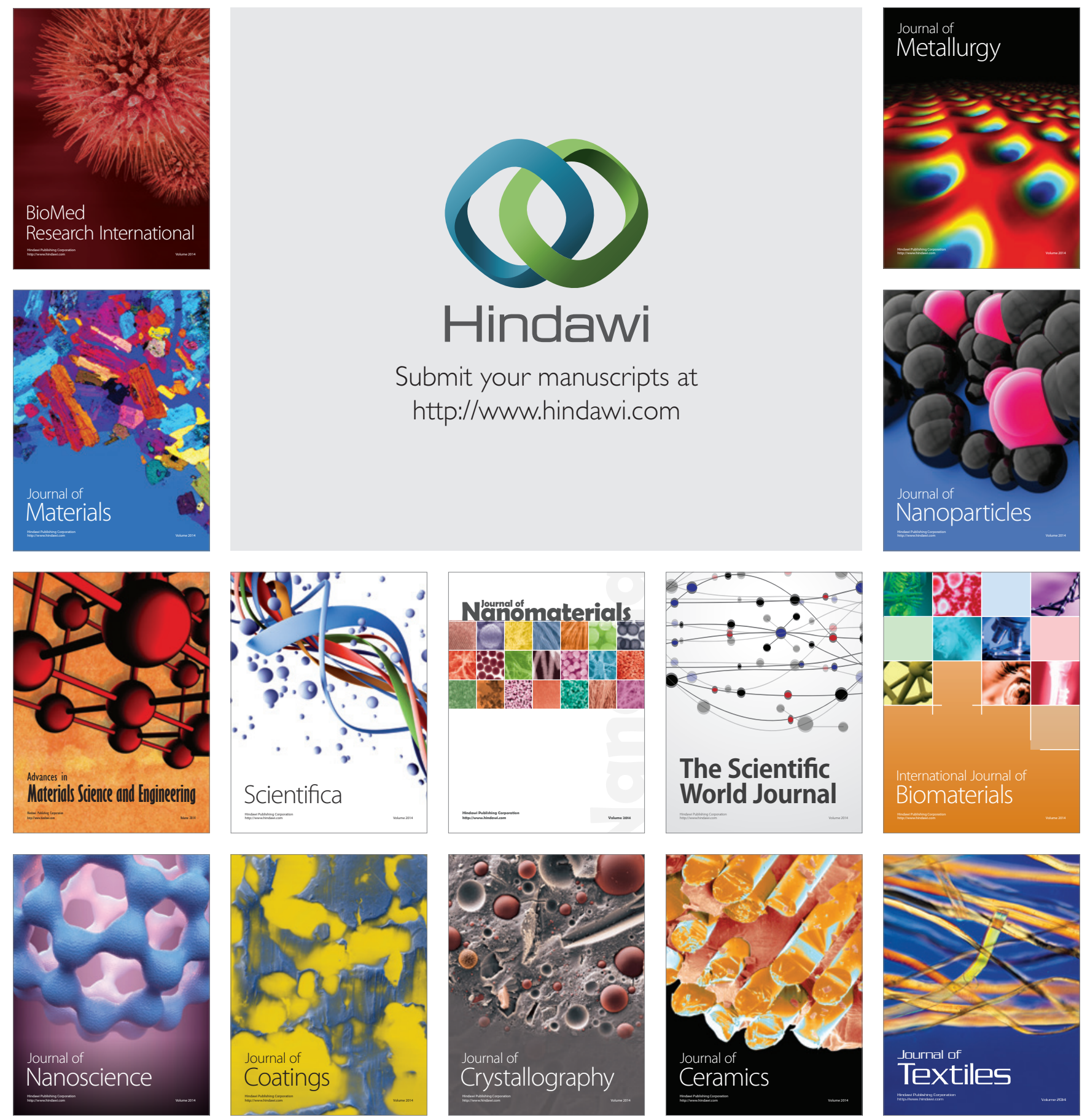